\title{
Pengaruh Gaya Kepemimpinan dan Motivasi Kerja Terhadap Kinerja Pembangunan \\ (The Influence of Leadership Style and Work Motivation on Development Performance )
}

\author{
Budi Hartono \\ Program Magister Ilmu Administrasi Universitas Jember \\ email: budihartono57.9@gmail.com
}

Received: 23 Januari 2018, Revised: 3 Februari 2018, Accepted: 20 Februari 2018

\begin{abstract}
Abstrak:
Tujuan penelitian ini adalah untuk mengetahui pengaruh antara gaya kepemimpinan, motivasi kerja dan kinerja pembangunan di desa Besuki Kecamatan Besuki Kabupaten Situbondo. Hasil penelitian menunjukan bahwa Gaya Kepemimpinan dan Motivasi Kerja baik secara simultan maupun parsial berpengaruh terhadap Kinerja pembangunan di desa Besuki Kecamatan Besuki Kabupaten Situbondo. Pembangun seperti rencana yang telah ditetapkan sangat bergantung pada kinerja seluruh stakeholder yang ada. Faktor yang sangat berpengaruh terhadap kinerja pembangunan di desa Besuki adalah faktor gaya kepemimpinan dan motivasi kerja dari seorang kepala desa sebagai pemimpin tertinggi di desa Besuki.
\end{abstract}

Kata kunci : gaya kepemimpinan, motivasi kerja, kinerja pembangunan

\begin{abstract}
:
The purpose of this research is to know the influence between leadership style, work motivation and development performance in Besuki village Besuki District Situbondo regency. The results showed that the style of leadership and work motivation both simultaneously and partially affect the performance of development in the village Besuki Besuki District Situbondo Regency. The builder of such a predetermined plan depends heavily on the performance of all existing stakeholders. The most influential factor on the development performance in Besuki village is the factor of leadership style and work motivation of a village head as the highest leader in Besuki village.

Keywords: leadership style, work motivation, development performance
\end{abstract}




\section{A. PENDAHULUAN}

\section{Latar Belakang}

Desa adalah entitas terkecil dari sistem pemerintahan dan menempati posisi strategis dalam proses pembangunan lebih-lebih pelaksanaan pembangunan di desa diharapkan bisa memberdayakan masyarakat. Menanamkan nilai-nilai budaya modern, seperti kerja keras, hemat, keterbukaan, dan kebertanggungjawaban adalah bagian pokok dari upaya pemberdayaan ini. Tujuan akhirnya adalah memandirikan masyarakat, memampukan, dan membangun kemampuan untuk memajukan diri ke arah kehidupan yang lebih baik secara berkesinambungan (Sumodiningrat, Gunawan, 2002). Semua itu sangat ditentukan oleh kepala desa sebagai pemimpin bisa memberikan motivasi kepada seluruh stakeholder agar program pembangunan bisa berjalan sesuai dengan harapan.

\section{Tujuan Penelitian}

Penelitian ini bertujuan untuk mengetahui :

1. Pengaruh Gaya Kepemimpinan terhadap Kinerja Pembangunan;

2. Pengaruh Motivasi Kerja terhadap Kinerja Pembangunan;

3. Pengaruh Gaya Kepemimpinan dan Motivasi Kerja terhadap Kinerja Pembangunan.

\section{B. TINJAUAN PUSTAKA}

\section{Manajemen Sumberdaya Manusia}

Menurut Manullang (2005:198) manajemen sumber daya manusia adalah seni dan ilmu pengadaan, pengembangan dan pemanfaatan sumber daya manusia sehingga tujuan organisasi direalisasi secara daya guna dan adanya kegairahan kerja dari semua tenaga kerja. Menurut Mondy (2010:4) manajemen sumber daya manusia adalah pemanfaatan individu untuk mencapai tujuan organisasi. 


\section{Kinerja Pembangunan}

Kinerja adalah kesediaan seseorang atau kelompok orang untuk melakukan sesuatu kegiatan dan menyempurnakannya sesuai dengan tanggung jawabnya dengan hasil seperti yang diharapkan.Rivai,dkk., (2005:15-16) Sedangkan Pengertian Pembangunan adalah suatu proses perubahan ke arah yang lebih baik melalui upaya yang dilakukan secara terencana Ginanjar Kartasasmita (1994). Jadi Kinerja pembangunan adalah kesediaan seseorang atau kelompok orang untuk melakukan perubahan sesuai dengan tanggungjawabnya ke arah yang lebih baik melalui upaya yang dilakukan secara terencana .

\section{Gaya Kepemimpinan}

Menurut Bass dan Avolio (1994) dalam Suwatno dan Priansa (2011:159), kepemimpinan memiliki 4 dimensi kepemimpinan transformasional yang dikenal dengan konsep "4I". Dimensi dan indikator kepemimpinan menurut Bass dan Avolio adalah: (a) Ideal pengaruh (Idealized influence), pemimpin harus menjadi contoh yang baik, yang dapat diikuti oleh karyawannya, (b) Inspirasi motivasi (Inspirational motivation), pemimpin harus bisa memberikan motivasi, dan target yang jelas untuk dicapai oleh karyawannya. (c) Intelektual stimulasi (Intellectual stimulation), pemimpin harus mampu merangsang karyawannya untuk memunculkan ide-ide dan gagasan-gagasan baru, (d)Individual konsider (Individualized consideration), pemimpin harus memberikan perhatian, mendengarkan keluhan, dan mengerti kebutuhan karyawannya.

\section{Motivasi Kerja}

Motivasi adalah kesediaan untuk mengeluarkan tingkat upaya yang tinggi untuk tujuan organisasi yang dikondisikan oleh kemampuan upaya itu untuk memenuhi beberapa kebutuhan individual. Sangadji dan Sopiah (2013:154).Adapun indikator yang digunakan adalah (1) Achievement motivation : adalah suatu keinginan untuk mengatasi/ mengalahkan suatu tantangan;(2) Affiliation motivation : adalah dorongan untuk melakukan hubungan dengan orang lain; (3) Competence motivation, adalah untuk melakukan pekerjaan yang 
bermutu;(4) Power motivation : adalah dorongan yang dapat mengendalikan suatu keadaan.

\section{Penelitian Terdahulu}

Penelitian yang dilakukan oleh Yoga Kusuma Wardhana pada tahun 2014 yang mana menyatakan bahwa hasil dari penelitian ini menunjukkan bahwa variabel gaya kepemimpinan, motivasi dan disiplin kerja berpengaruh secara signifikan terhadap kinerja pegawai. Secara parsial variabel motivasi tidak berpengaruh secara signifikan terhadap kinerja pegawai sedangkan variabel gaya kepemimpinan dan disiplin kerja berpengaruh secara signifikan terhadap kinerja pegawai pada tingkat signifikan kurang dari 0,05 atau 5\%.

Penelitian yang dilakukan oleh Sindu Pradipto pada tahun 2015 yang mana menyatakan bahwa hasil analisis dan pembahasan maka dapat disimpulkan bahwa: (1) Gaya kepemimpinan berpengaruh positif secara signifikan terhadap kinerja karyawan (2) Disiplin kerja berpengaruh positif secara signifikan terhadap kinerja karyawan (3) Gaya kepemimpinan berpengaruh secara positif dan signifikan terhadap motivasi kerja.

\section{Kerangka Konseptual}

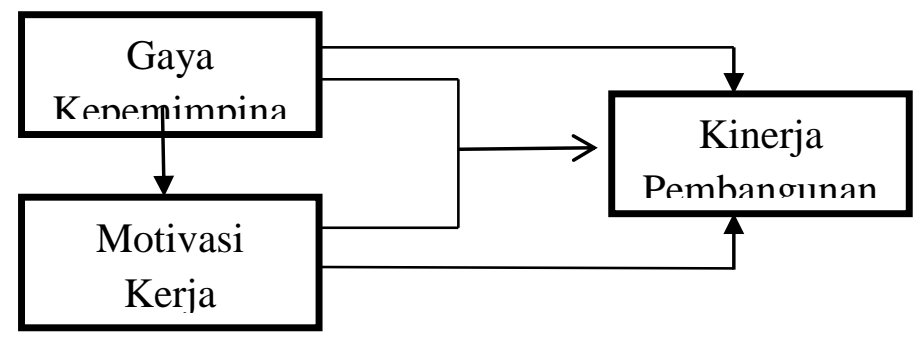

Gambar 1 : Kerangka Konseptual

Sumber : Konsep diolah 2017 


\section{Hipotesis Penelitian}

H1 : Gaya Kepemimpinan berpengaruh terhadap kinerja pembangunan;

H2 : Motivasi Kerja berpengaruh terhadap kinerja pembangunan;

H3 : Gaya kepemimpinan dan motivasi kerja berpengaruh terhadap kinerja pembangunan.

\section{METODE PENELITIAN}

\section{Jenis Penelitian}

Dilihat dari tingkat eksplanasi diklasifikasikan pada jenis penelitian asosiasi. Penelitian asosiasi adalah penelitian yang menanyakan hubungan antara dua variabel atau lebih, Sugiyono (2010:69). Penelitian ini menjelaskan tentang motivasi kerja, gaya kepemimpinan dan hubungan terhadap kinerja pegawai.

\section{Teknik Pengumpulan Data}

Metode yang digunakan dalam penelitian ini adalah wawancara (Tanya Jawab), Kueisioner (Daftar pertanyaan), Metode penelitian kepustakaan (Library Research Method) yaitu pengumpulan data dari beberapa literatur dan karya ilmiah dari berbagai ahli yang berhubungan dengan penelitian ini.

\section{Populasi Dan Teknik Pengambilan Sampel}

Populasi dalam penelitian ini adalah seluruh pengurus harian Rukun Tetangga ( RT ) terdiri dari Ketua,sekretaris,dan bendahara tiap RT. Jumlah Rukun Tetangga ( RT ) di desa Besuki berjumlah 76 sehingga jumlah populasi seluruhnya adalah $76 \times 3=228$ orang. Populasi adalah keseluruhan subjek penelitian (Arikunto, 2010:173). Sampel adalah bagian dari jumlah dan karakteristik yang dimiliki oleh populasi (Sugiyono, 2010:116). Sampel adalah sebagian atau wakil populasi yang diteliti. Dinamakan sampel jika peneliti bermaksud untuk menggeneralisasikan hasil penelitian sampel. Teknik pengambilan sampel dalam penelitian ini menggunakan Simple random sampling. Teknik random sampling adalah teknik pengambilan sampel dimana semua individu dalam populasi, baik secara sendiri-sendiri atau bersama-sama diberi kesempatan yang sama untuk dipilih menjadi anggota sampel. Teknik menentukan 
besaran sampel dalam penelitian ini menggunakan rumus Slovin. (Umar, 2004:108) sebagai berikut:

$n=\frac{N}{1+N e^{2}}$

Di mana:

$\mathrm{n} \quad=$ ukuran sampel

$\mathrm{N} \quad=$ ukuran populasi

$\mathrm{e} \quad=$ error

Maka perhitungan dalam pengambilan sampel adalah sebagai berikut:

$n=\frac{228}{1+\left(228 \times 0.05^{2}\right)}$

$n=\frac{228}{1+0.57}$

$n=\frac{228}{1.57}$

$n=145.2$

Dibulatkan menjadi 145

\section{Metode Analisis Data}

\section{a. Uji Validitas}

Uji validitas digunakan untuk mengukur apakah suatu instrument alat ukur telah menjalankan fungsi ukurnya. Dengan membandingkan nilai $r$ hitung dengan $\mathrm{r}$ tabel, Jika $\mathrm{r}$ hitung $>\mathrm{r}$ tabel maka pertanyaan atau indikator tersebut dinyatakan valid, demikian sebaliknya, Wijaya (2012:119).

\section{b. Uji Reliabilitas}

Uji reliabilitas dilakukan untuk mengetahui tingkat kestabilan suatu alat ukur. suatu konstruk atau variabel dikatakan reliable jika memberikan nilai Cronbach Alpha > 0.6, Wijaya (2012:116).

\section{c. Uji Asumsi Klasik}

Untuk mengetahui bahwa model regresi linier berganda dalam penelitian ini dapat disebut sebagai model yang baik. Maka model ini harus diuji dengan uji normalitas, multikolinearitas, dan heteroskesdastisitas, agar dapat diketahui 
apakah model regresi linier berganda dalam penelitian ini telah terbebas dari asumsi-asumsi klasik statistik.

\section{d. Analisis Regresi Linier Berganda}

Penggunaan analisis regresi linear berganda pada penelitian ini bertujuan untuk mengetahui ada tidaknya pengaruh dari variabel independen terhadap variabel dependen. Hasil pengelolahan data pada peneltian ini menggunakan program SPSS for windows versi 20.0, yang ringkasan hasilnya dapat digambarkan pada tabel berikut:

Tabel Analisis Regresi

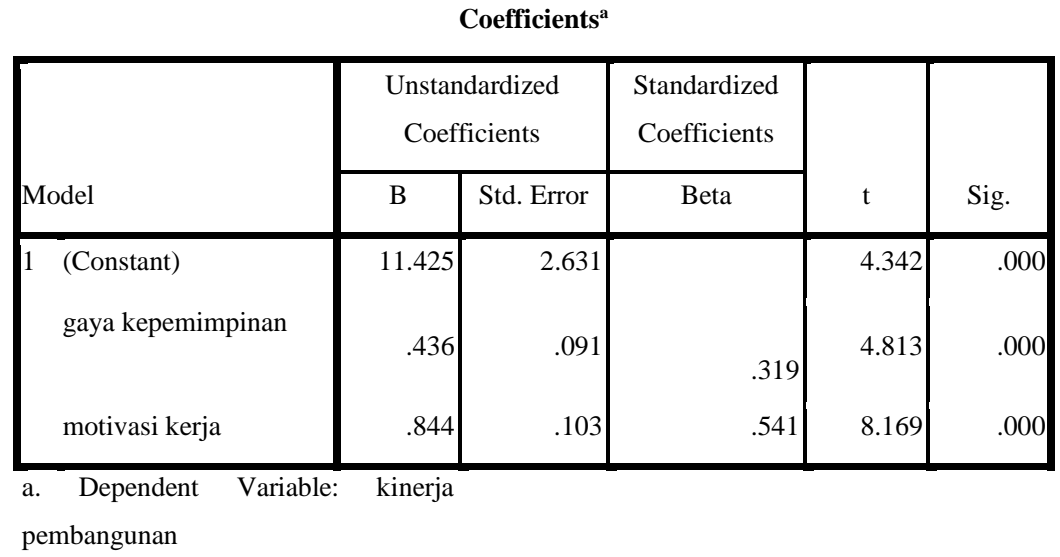

Berdasarkan tabel di atas, maka diperoleh persamaan regresi sebagai berikut:

$Y=0.436 \times 1+0.844 \times 2$

Keterangan:

$\mathrm{Y}=$ Kinerja Pembangunan ,X1 = Gaya Kepemimpinan ,X2 = Motivasi Kerja

Dengan melihat persamaan regresi linier di atas, maka dapat dijelaskan bahwa: 1. Nilai koefisien Gaya Kepemimpinan sebesar 0.436. Hal ini mengandung arti bahwa apabila gaya kepemimpinan naik satu satuan maka variable kinerjapembangunan akan naik sebesar 0.436 dengan asumsi bahwa variable bebas yang lain dari regresi adalah tetap.

2. Nilai koefisien Motivasi kerja sebesar 0.844. Hal ini mengandung arti bahwa setiap kenaikan motivasi kerja satu satuan maka variable kinerja pembangunan 
akan naik sebesar 0.844 dengan asumsi bahwa variable bebas yang lain dari regresi adalah tetap.

\section{e. Uji statistik}

Meliputi uji-F, uji-t, dan uji-R2. Dimana untuk melihat apakah variabel independen memiliki/ mempunyai pengaruh yang signifikan terhadap variabel dependen.

\section{HASIL PENELITIAN DAN PEMBAHASAN}

\section{Hasil Penelitian}

\section{a. Hasil Uji Validitas}

Berdasarkan hasil rekapitulasi data yang tersaji dalam tabel, nilai $\mathrm{r}$ hitung untuk semua item pertanyaan yang digunakan untuk mengukur variabel gaya kepemimpinan ,motivasi kerja maupun kinerja pembangunan semuanya bernilai lebih dari p. dan dianggap valid serta dapat digunakan untuk mendapatkan datadata penelitian.

\section{b. Hasil Uji Reliabilitas}

Berdasarkan uji reliabilitas instrumen dengan menggunakan program SPSS 20.00 dihasilkan data sebagai berikut:

Tabel 4.12

Hasil Uji Reliabilitas

\begin{tabular}{|l|c|c|c|}
\hline \multicolumn{1}{|c|}{ Variabel } & $\begin{array}{c}\text { Alpha } \\
\text { Cronbach }\end{array}$ & Nilai Kritis & Keterangan \\
\hline Gaya kepemimpinan & 0,838 & 0,70 & Reliabel \\
\hline Motivasi Keja & 0,788 & 0,70 & Reliabel \\
\hline Kinerja Pembangunan & 0,909 & 0,70 & Reliabel \\
\hline
\end{tabular}

Sumber: data primer yang diolah, 2017

Berdasarkan table diatas menunjukkan bahwa item pertanyaan dari variable gaya kepemimpinan, motivasi kerja dan kinerja Pembangunan berstatus reliabel terlihat dari koefisien alpha yang positif bernilai lebih besar dari 0,70 . 


\section{c.. Hipotesis Penelitian}

\section{Uji t}

Berikut ini merupakan ringkasan hasil uji t:

Tabel Hasil uji t

Sumber: data primer yang diolah, 2017

\begin{tabular}{|l|c|c|c|}
\hline \multicolumn{1}{|c|}{ Variabel } & T & Nilai Sign & Keterangan \\
\hline Gaya kepemimpinan & 4.813 & .000 & Signifikan \\
\hline Motivasi Kerja & 8.169 & .000 & Signifikan \\
\hline
\end{tabular}

Berdasarkan tabel hasil uji t dapat diketahui bahwa perhitungan SPSS diperoleh t hitung sebesar 4.813 dengan nilai probabilitas (nilai sig) 0.000.Nilai probabilitas tersebut lebih kecil dari alpha (5\%). Dengan demikian dapat disimpulkan bahwa variabel gaya kepemimpinan berpengaruh terhadap Kinerja. Berdasarkan table hasil uji t dapat diketahui diperoleh t hitung sebesar 8.169 dengan nilai probabilitas (nilai sig) 0.000.Nilai probabilitas tersebut lebih kecil dari alpha (5\%).Dengan demikian dapat disimpulkan bahwa variabel motivasi kerja berpengaruh terhadap Kinerja pembangunan.

\section{Uji F}

Uji F dilakukan untuk mengetahui apakah pengaruh antara variabel bebas dengan variable terikat bersifat liner. Adapun dengan cara melihat nilai probabilitas pada tabel ANOVA berikut:

\section{Tabel Hasil Uji F}

ANOVA $^{\mathbf{b}}$

\begin{tabular}{|l|r|r|r|r|r|}
\hline \multicolumn{1}{|c|}{ Model } & Sum of Squares & df & Mean Square & F & Sig. \\
\hline $1 \quad$ Regression & 2592.736 & 2 & 1296.368 & 108.115 & $.000^{\mathrm{a}}$ \\
Residual & 1702.671 & 142 & 11.991 & & \\
Total & 4295.407 & 144 & & & \\
\hline
\end{tabular}

a. Predictors: (Constant), motivasi kerja, gaya kepemimpinan

b. Dependent Variable: kinerja pembangunan 
Sumber: data primer yang diolah, 2017

Dari hasil perhitungan dengan SPSS terlihat bahwa nilai $\mathrm{F}$ hitung adalah sebesar 108.115 dengan nilai probabilitas (nilai sig) sebesar 0.000. Nilai probabilitas tersebut lebih kecil dari nilai alpha $(0,05)$. Karena nilai probabilitas (p-value) <alpha maka dapat disimpulkan bahwa pengaruh variabel gaya kepemimpinan dan motivasi kerja terhadap Kinerja pembangunan bersifat signifikan.

\section{Koefisien Determinan}

Koefisien determinasi atau nilai adjusted R2 adalah pengukuran dari nilai koefisien korelasi (R). Hasil penghitungan dapat dilihat pada tabel berikut ini:

Hasil Koefisien Determinan

Model Summary

\begin{tabular}{|l|c|c|c|c|}
\hline Model & $\mathrm{R}$ & $\mathrm{R}$ Square & Adjusted R Square & Std. Error of the Estimate \\
\hline 1 & $.777^{\mathrm{a}}$ & .604 & .598 & 3.46275 \\
\hline
\end{tabular}

Sumber: data primer yang diolah, 2017

Nilai R yang tersaji di atas sebesar 0.777 , sedangkan nilai $\mathrm{R}^{2}$ yang tersaji pada tabel di atas menunjukkan nilai 0.604 atau 60,4\% Hal ini dapat diartikan bahwa sebanyak 60,4\% Kinerja pembangunan dijelaskan oleh variabel gaya kepemimpinan dan motivasi kerja. Sedangkan sisanya sebesar 39,6\% dijelaskan oleh variabel lain di luar variabel kinerja pembangunan. 


\section{Pembahasan}

\section{a. Pengaruh Gaya Kepemimpinan Terhadap Kinerja Pembangunan}

Hasil penelitian menyebutkan adanya pengaruh antara variabel gaya kepemimpinan terhadap kinerja pembangunanberdasarkan tabel hasil uji $t$ dapat diketahui bahwa perhitungan SPSS diperoleh t hitung sebesar 4.813 dengan nilai probabilitas (nilai sig) 0.000 . Nilai probabilitas tersebut lebih kecil dari alpha (5\%)dan dapat disimpulkan bahwa variabel gaya kepemimpinan berpengaruh terhadap Kinerja pembangunan.

\section{b. Pengaruh Motivasi Kerja terhadap Kinerja Pembangunan}

Kinerja karyawan merupakan hal penting yang harus diperhatikan oleh setiap organisasi. Kinerja karyawan di Desa Besuki Kecamatan Besuki Kabupaten Situbondo merupakan faktor yang sangat penting dalam melaksanakan program pembangunan desa, karena kinerja pembangunan desaditentukan oleh kinerja karyawan. Berdasarkan hasil penelitian yang dilakukan oleh peneliti menyatakan bahwa terdapat pengaruh antara motivasi kerja terhadap kinerja pembangunan.Hal ini dapat dilihat berdasarkan tabel hasil uji t dapat diketahui bahwa perhitungan SPSS diperoleh $\mathrm{t}$ hitung sebesar 8.169 dengan nilai probabilitas (nilai sig) 0.000.Nilai probabilitas tersebut lebih kecil dari alpha (5\%).Dengan demikian dapat disimpulkan bahwa variabel motivasi kerja berpengaruh terhadap Kinerja Pembangunan.

\section{c. Pengaruh Gaya Kepemimpinan dan Motivasi Kerja terhadap Kinerja} Pembangunan

Berdasarkan hasil penelitian disimpulkan bahwa terdapat pengaruh antara gaya kepemimpinan dan motivasi kerja terhadap kinerjapembangunan .Hal ini dapat terlihat berdasarkan hasil perhitungan dengan SPSS terlihat bahwa nilai $\mathrm{F}$ hitung adalah sebesar 108.115 dengan nilai probabilitas (nilai sig) sebesar 0.000. Nilai probabilitas tersebut lebih kecil dari nilai alpha $(0,05)$. Karena nilai probabilitas (p-value) <alpha maka dapat disimpulkan bahwa pengaruh variabel gaya kepemimpinan dan motivasi kerja terhadap Kinerjapembangunan bersifat signifikan. 


\section{E. Kesimpulan dan Saran}

\section{Kesimpulan}

Berdasarkan hasil penelitian dan pembahasan yang telah diuraian sebelumnya, maka dapat ditarik kesimpulan sebagai berikut:

1) Gaya kepemimpinan berpengaruh terhadap kinerja pembangunan di Desa Besuki Kecamatan Besuki Kabupaten Situbondo.

2) Motivasi kerja berpengaruh terhadap kinerja pembangunan di Desa Besuki Kacamatan Besuki Kabupaten Situbondo.

3) Gaya kepemimpinan dan motivasi kerja berpengaruh terhadap kinerja pembangunan di Desa Besuki Kecamatan Besuki Kabupaten Situbondo.

\section{Saran}

Adapun saran dalam penelitian ini adalah

1) Lebih ditingkatkan kembali dalam gaya kepemimpinan dan motivasi kerja sehingga dapat tercipta kinerja pembangunan yang optimal pada desa Besuki Kecamatan Besuki Kabupaten Situbondo.

2) Penelitian ini diharapkan bisa menjadi bahan untuk menambah ilmu pengetahuan dan wawasan, serta menjadi informasi tambahan dan bahan pembelajara. Kepada peneliti lainnya diharapkan dapat melakukan penelitian lanjutan tentang kinerja pembangunan, karena masih banyak factor lain yang dapat mempengaruhi rendahnya kinerja pembangunan. 


\section{DAFTAR PUSTAKA}

Arikunto, S. 2013. Prosedur penelitian: Suatu Pendekatan Praktik. (Edisi Revisi). Jakarta : Rineka Cipta

Dessler, Gary. 2015. Manajemen Sumber Daya Manusia. Alih bahasa: Eli Tanya. Penyunting Bahasa: Budi Supriyanto. Jakarta: Indeks.

M.Manullang, 2012. Dasar-dasar Manajemen.Gadjah Mada University Press.P.O.BOX 14,Bulaksumur,Jogjakarta.

Mondy, R. Wayne, 2010, Human Resource Management .Eleventh Edition. New Jersey: Prentice Hall.

Rivai, Veithzal. \& Sagala, E.J. 2009. Manajemen Sumber Daya Manusia Untuk Perusahaan. Jakarta: Rajagrafindo Persada.

Sangadji, E.M., dan Sopiah. 2013. Prilaku Konsumen: Pendekatan PraktisDisertai:Himpunan Jurnal Penelitian. Yogyakarta: Penerbit Andi.

Sugiyono. 2010. Metode Penelitian Kuantitatif \& RND. Bandung: Alfabeta.

Sumodiningrat,Gunawan, 2002, Pemberdayaan Masyarakat dan Jejaring Sosial.Jakarta,Gramedia Pustaka Utama.

Suwatno. \& Donni Juni Priansa. 2011. Manajemen SDM dalam Organisasi Publik Dan Bisinis. Bandung: Alfabeta.

Wardhana, Yoga Kusuma. 2014. Pengaruh Gaya Kepemimpinan, Motivasi dan Disiplin Kerja terhadap Kinerja. Jakarta: Universitas Islam Negeri Syarif Hidayatullah. 